\title{
ECHOGRAPHIC FINDINGS IN FETUS WITH TURNER SYNDROME - A CASE REPORT
}

\author{
TÁBATA DE O. SILVA, CARLOS EDUARDO L. DE S. CRUZ, JOÃO PEDRO C. CORREIA, PAULA DE O. SILVA, JOBE PETTER
}

\begin{abstract}
Turner Syndrome (TS) is the congenital hypoplastic ovarian syndrome that occurs in the absence or partiality of the $X$ chromosome and by instability of the $Y$ chromosome, which causes loss during meiosis. Diagnosis by ultrasound examination in the 1st and 2nd trimester is essential to identify phenotypic changes and associated complications with the pathology, such as those seen in the current case.
\end{abstract}

\section{KEYWORDS: TURNER SYNDROME, FETAL MEDICINE, CHROMOSOMAL DISEASE, NUCHAL TRANSLUCENCY, ULTRASONOGRAPHY}

\section{INTRODUCTION}

Turner syndrome is an anomaly with partial or complete loss of the $\mathrm{X}$ chromosome, which is more common in fetuses of women younger than 35 years (about 3\% of all). The phenotypic severity occurs according to the dimension of the $\mathrm{X}$ chromosome loss, and it can affect several systems such as the skeletal, cardiovascular, lymphatic, endocrine, gastrointestinal, renal, auditory, visual and central nervous systems. This is the only monomeric syndrome in which humans can survive. The mortality rate is higher than that of people without this change due to its correlation with cardiovascular changes and autoimmune diseases. 1,2

Cardiovascular complications (mosaicism 45, X) occur in about $41 \%$ of patients, the most common being cardiac valve disease and bicuspid aortic deformity, but patients with TS may present with partial anomalous pulmonary connection and persistent left superior vena cava. Furthermore, abnormalities in electrical physiology such as QT prolongation, $\mathrm{T}$ wave alteration and increased atrioventricular conduction are observed. It is important that these are monitored by a cardiologist through echocardiography and electrocardiography, respectively. ${ }^{3}$ It is also related to other diseases that can lead to thyroiditis (in approximately $3.2 \%$ of cases), colitis, celiac disease, type 1 diabetes and psoriasis. 1,4

The incidence ranges from 1:2500 to 1:3000 live-born girls due to the high frequency of miscarriages. About $70 \%$ of cases of Turner syndrome diagnosed in the 2 nd trimester will result in miscarriages between the 16th week and term. The 45,X karyotype is seen in 1\% of stillbirths, about $10 \%$ of miscarriages, and $2 \%$ of live births. ${ }^{1,4}$

The $45, \mathrm{X}$ karyotype is associated with more abnormal- ity and is the most severe phenotype, in which of women the X chromosome is of maternal origin. $45 \mathrm{X} / 46 \mathrm{XY}$ TS mosaicism has a higher risk for promoting gonadoblastoma (a rare neoplasm in the GBY critical region), whereas the $\mathrm{Xq}$ isochromosome is a structural change that is associated with autoimmune diseases and deafness. The $45 \mathrm{X} / 46 \mathrm{XX}$ karyotype is the least severe phenotype. ${ }^{4}$

With regard to clinical manifestations, the main evidence is short stature (PAR1 gene located on the short arm of the X chromosome) in which final height is between 143 and $147 \mathrm{~cm}$, as well as short neck, high arched palate, wide chest, dysplasia of the nails, genu valgum, premature ovarian failure (due to haploinsufficiency of a gene, which may be ZFX or DFFRX) and renal abnormalities (double collecting system or absence of kidney), skeletal (vertebral hypoplasia that contributes to short stature, short neck and scoliosis), metabolic (hypothyroidism), lymphedema (present in fetuses with mosaicism $45, \mathrm{X}$ ) and inflammatory gastrointestinal disease that have a high risk of developing Crohn's disease and ulcerative colitis (about twice as much). 1, 4,5

We present a case of intrauterine chromosomal diagnosis, and the respective phenotype, both in the first trimester screening and in the 2 nd trimester morphological study.

\section{CASE PRESENTATION}

A 25-year-old female patient underwent ultrasound screening for first trimester chromosome disorders at 12 weeks and 3 days. The examination was performed by a physician specialized in diagnostic imaging using equipment with a convex volumetric transducer via the transabdominal route, following the standard proposed by the Fetal Medi-
1. Centro Universitário do Planalto Central Apparecido dos Santos, Gama, Brasília, DF.

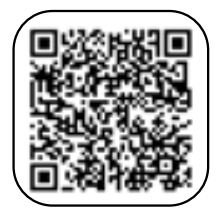

MAILING ADDRESS

JOBE PETTER

e-mail: jobe.petter@uniceplac.edu.br 
cine Foundation.

At 23 weeks and 2 days, the 2 nd trimester morphological study was carried out with the same medical specialist and equipment.

\section{IMAGE FINDINGS}

The images from the first trimester exam show $\mathrm{Nu}^{-}$ chal translucency (NT) measuring $7 \mathrm{~mm}$, unidentified nasal bone, ductus venosus with IP of 0.99 ( $>$ 95th percentile), no pathological tricuspid regurgitation and heart rate of 170 beats per minute (bpm). (Figures 1 to 3 ).

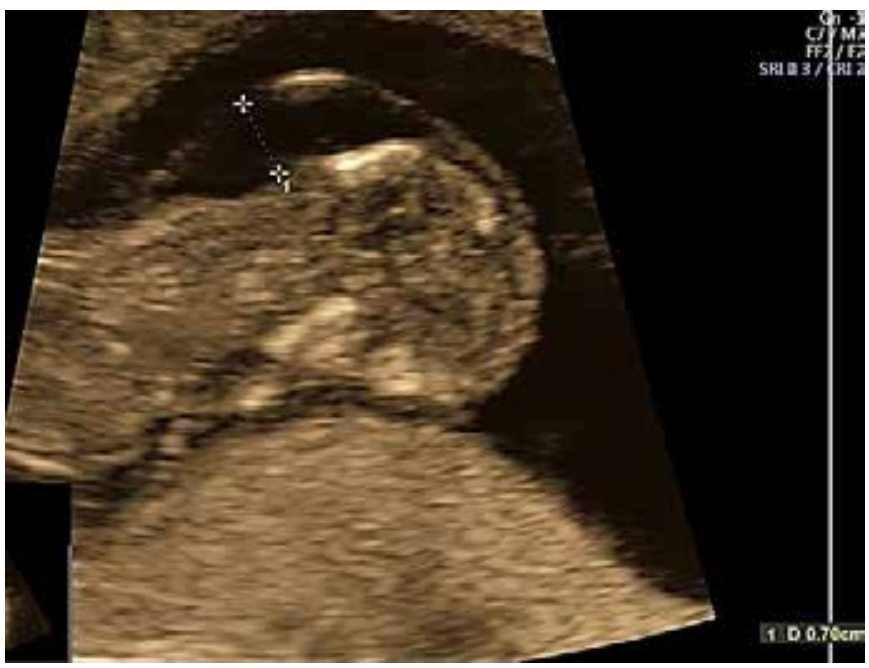

Figure 1 - Chromosomal markers: unidentified nasal bone and $7 \mathrm{~mm}$ increased nuchal translucency.

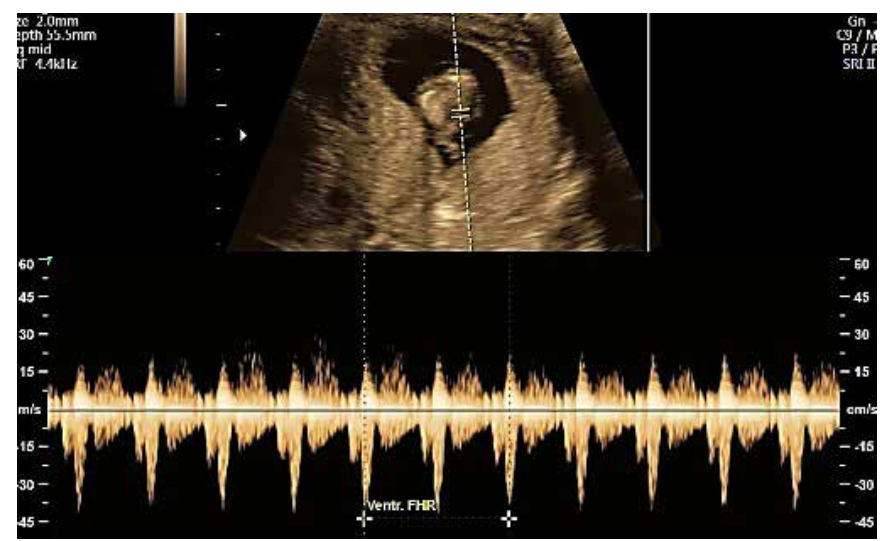

Figure 2 - Fetal heart rate of 170 beats per minute (bpm).

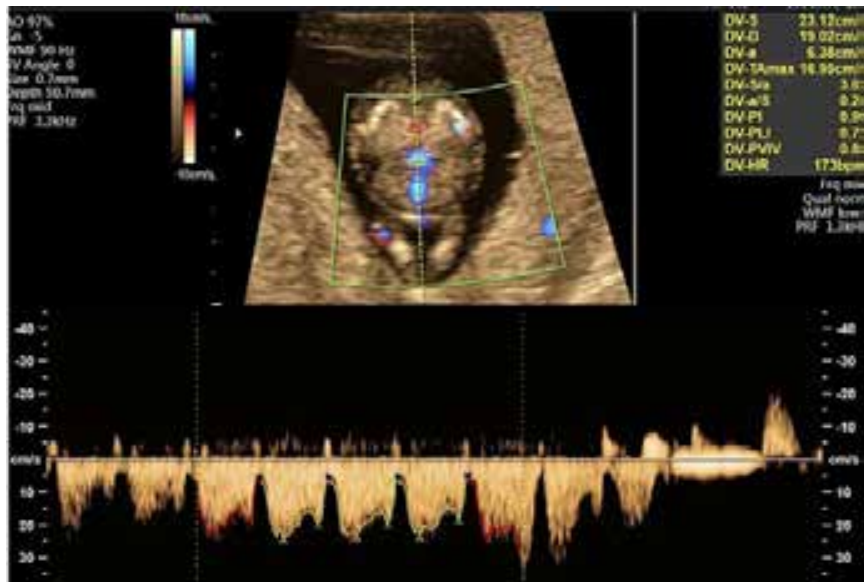

Figure 3 - Duct venosus with " $\mathrm{A}$ " wave present and Pulsatility Index (PI) of 0.99 .

Karyotype research was performed in amniotic fluid and $45, X$ was detected in all analyzed cells.

The morphological images of the second trimester show Cystic hygroma, generalized edema, pleural effusion, enlargement of the right chambers of the heart, bilateral renal hypoplasia and hyperechogenicity, bladder very little full and bilaterally framed by the respective umbilical arteries, and anhydramnios. (fig. 4 to 9 )

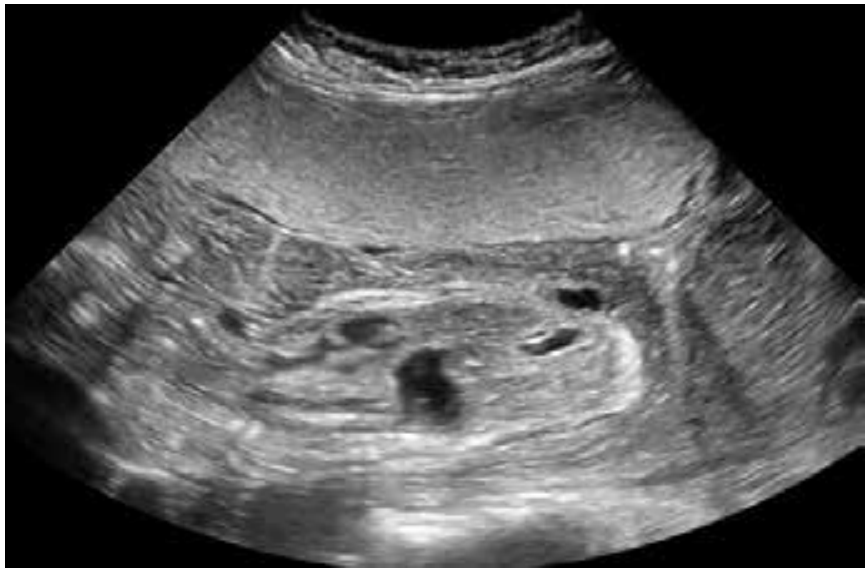

Figure 4 - Second trimester ultrasound at 23 weeks and 2 days, performed in a longitudinal situation, breech presentation, posterior dorsum, anhydramnios 


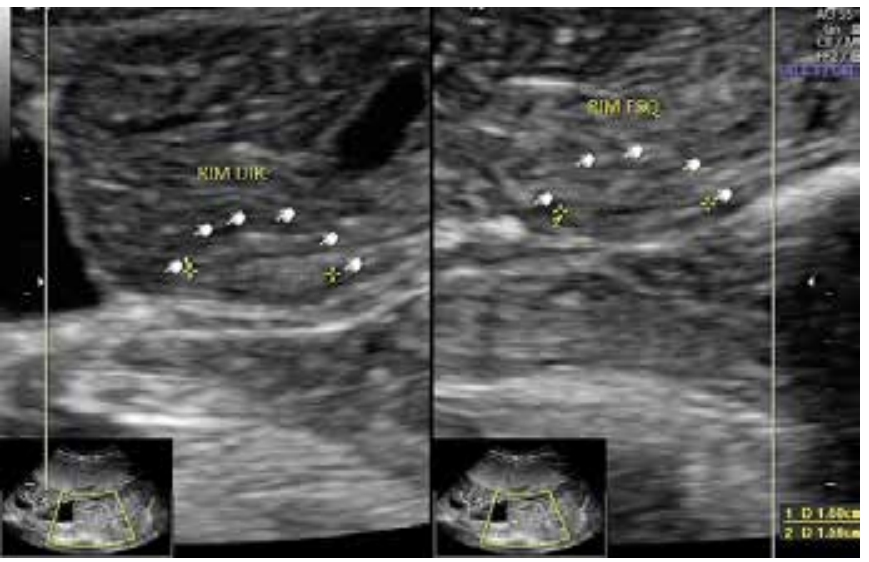

Figure 5- Images of the kidneys with increased echogenicity and decreased dimensions.

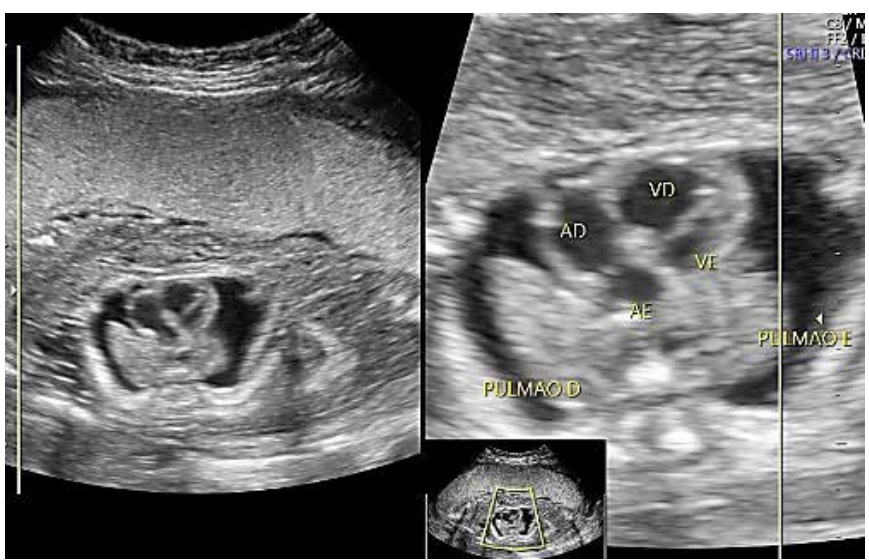

Figure 6 - 4-chamber view showing dominant right chambers and bilateral pleural effusion.

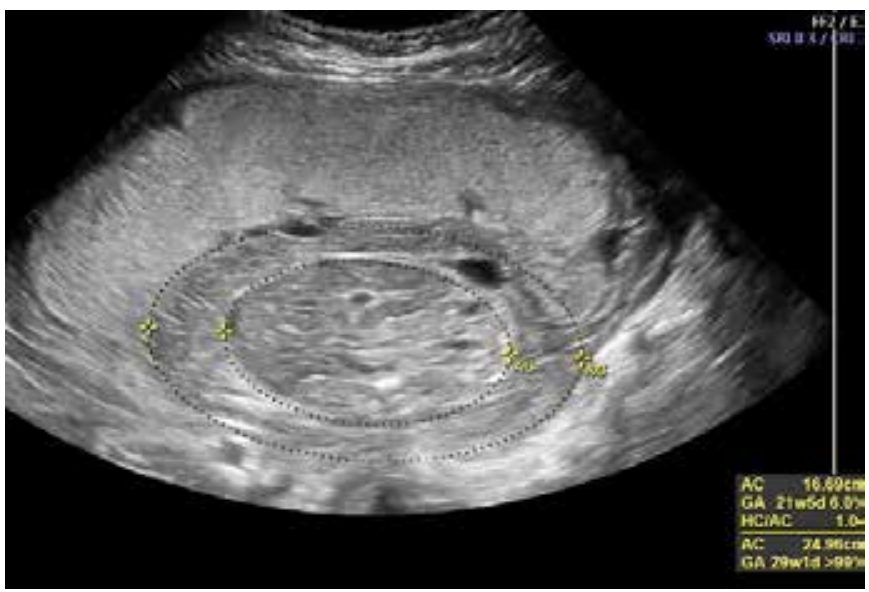

Figure 7 - Plan of the abdomen with anasarca and it is not possible to identify the gastric bubble.

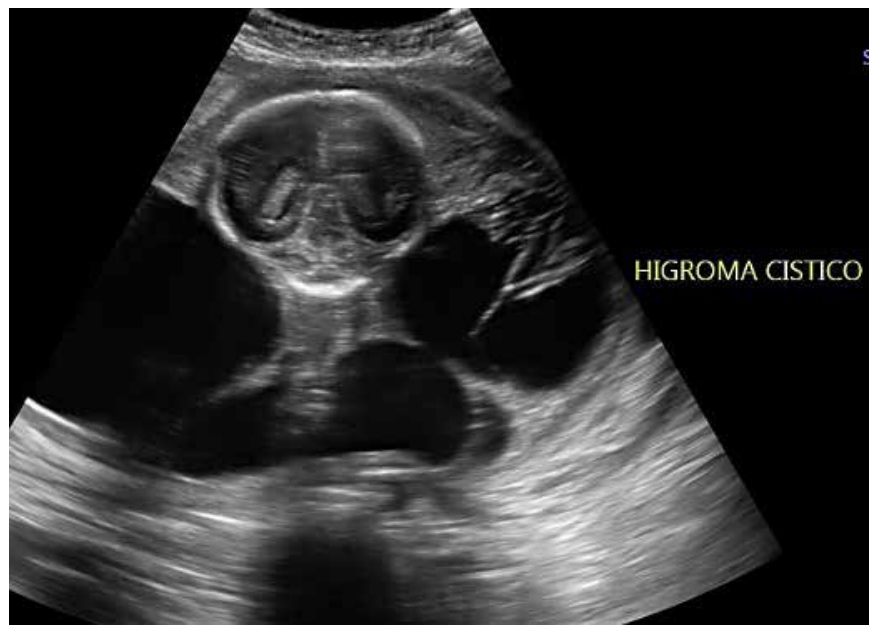

Figure 8 - Large cystic hygroma.

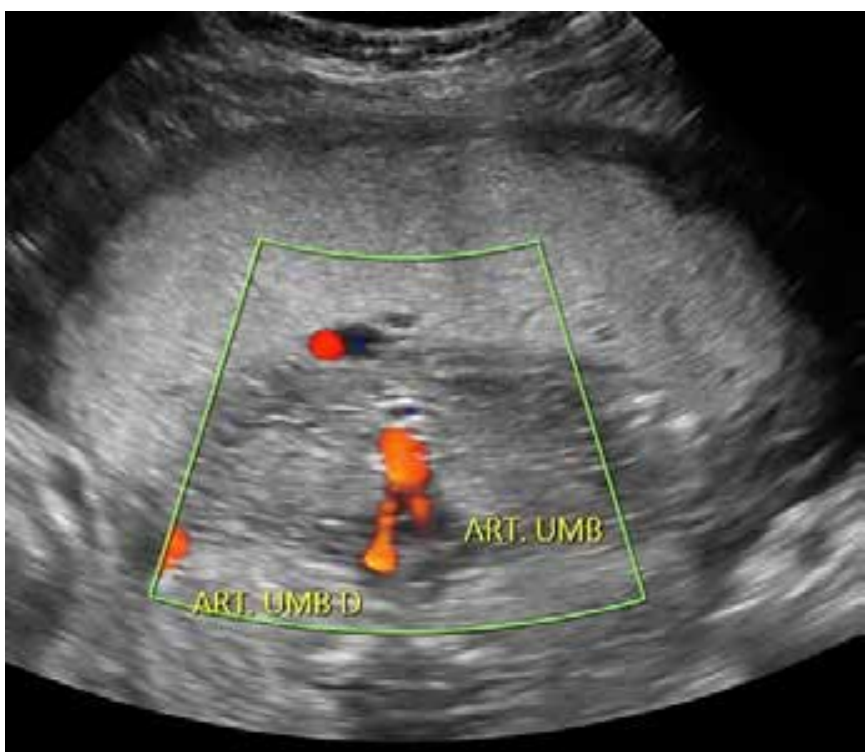

Figure 9 - Virtually empty bladder framed by the umbilical arteries.

\section{DISCUSSION}

The diagnosis of TS occurs during the prenatal examination using ultrasound or by signs of lymphedema or congenital heart disease. It is also necessary to perform a complete analysis of the karyotype to have a correct diagnosis of the pathology. ${ }^{1}$

Transvaginal echocardiography in the 1st trimester is a useful method to determine early-stage fetal cardiac alterations, but this method is not easily accessible for the entire health system, as it requires high-quality equipment often found only at the tertiary level of care. ${ }^{6}$

In the 1st trimester ultrasound, the characteristics that can favor the diagnosis of TS are: short femur, narrow aortic arch, cardiac defects on the left side (coarctation of the aor- 
ta). ${ }^{7}$ Screening is performed by neural tube defects, maternal serum alpha-fetoprotein, high levels of HCG, low levels of estriol, and detection of acetylcholinesterase in amniotic fluid. Ultrasound tracking is done by measuring NT between 10 and 14 weeks of gestation. $2,8,9,10$

Other criteria that favor the diagnosis are the measurement of the crown - rump length (minimum of $45 \mathrm{~mm}$ and maximum of $84 \mathrm{~mm}$ ), the analysis of the ductus venosus to verify the pattern of the pulsatility index above the 95th percentile for gestational age and the karyotyping by chorionic villus biopsy (repeat postnatally for confirmation), which can be performed in the presence of a clinical feature such as cystic hygroma or fetal hydrops. ${ }^{8.10}$

The use of molecular methods will quantify the polymerase chain reaction (PCR) genes by identifying the sites that are occurring specific $\mathrm{CpG}$ methylation to inactivate the $\mathrm{X}$ chromosome. Fluorescent in situ hybridization (FISH) test can be considered in virilized girls and when the Y chromosome was not displayed by standard karyotype analysis. Other confirmation methods are sequencing technologies such as genomes, exomes and the genetic panel ${ }^{1,10}$.

In the first trimester, cystic hygroma is relatively associated with fetal autosomal aneuploidy ${ }^{5,6}$. In the second trimester, this finding tends to be associated with TS, manifesting itself through generalized edema, pre-ductal aortic coarctation and decreased number of lymphatic vessels. ${ }^{2}$

Ultrasound findings are frequent in fetuses with TS, being much more frequent in non-mosaic cases ( $92 \times 55 \%$ ). The most common structural anomalies are: cystic hygroma; non-immune hydrops; severe subcutaneous edema; cardiac alterations (the most frequent ones are predominance of the right heart and coarctation of the aorta); and genitourinary alterations (mainly those related to the kidneys). ${ }^{7}$

\section{CONCLUSION}

Prenatal ultrasonography is the main screening tool for the diagnosis of TS even with the incorporation of other tests in routine clinical practice, the high sensitivity and specificity associated with the low cost and easy access of the exam makes it the first choice for prenatal screening. The documented findings and their severity are compatible with the karyotype and those described in the literature. The case progressed to fetal death.

\section{BIBLIOGRAPHIC REFERENCES}

1. Cui X, CuiY, Shi L, Luan J, Zhou X, Han J. A basic understanding of Turner syndrome: incidence, complications, diagnosis, and treatment. Intractable E Rare Diseases Research, 2018;7(4): 223-228.

2. Baena N, De Vigan C, Cariati E, Clementi M, Stoll C, Caballín MR, Guitart M. Turner syndrome: evaluation of prenatal diagnosis in 19 European registries. Am J Med Genetics 2004;129(1): 16-20.

3. Negrea SL, Alexandrescu C, Sabatier M, Dreyfus GD. Cleft posterior mitral valve leaflet in an adult with Turner syndrome diagnosed with the use of 3-dimensional transesophageal echocardiography. Texas Heart Institute Journal, 2012;39(4): 547.

4. Elsheikh M, Dunger D, Conway GS, Wass JAH. Turner's syndrome in adulthood. Endocrine Reviews, 2002;23(1): 120-140.

5. Klálsková E, Tüdös Z, Sobek A, Zapletalová J, Dostál J, Zbo ilová B, Sobek
AJr, Adamová K, Lattová V, Dostálová Z, Procházka M. Low level 45, $\mathrm{X} / 46, \mathrm{XX}$ mosaicism is not associated with congenital heart disease and thoracic aorta dilatation: prospective magnetic resonance imaging and $\mathrm{ul}$ trasound study. Ultrasound in Obstetrics \& Gynecology, 2015;45(6): 722727.

6. Haak MC, Bartelings MM, Gittenberger-De Groot AC, Van Vugt JMG. Cardiac malformations in first trimester fetuses with increased nuchal translucency: ultrasound diagnosis and postmortem morphology. Ultrasound in Obstetrics and Gynecology, 2002;20(1): 14-21.

7. Wiechec M, Knafel A, Nocun A, Wiercinska E, Ludwin A, Ludwin I. What are the most common first-trimester ultrasound findings in cases of Turner syndrome? J Matern Fetal Neonatal Med. 2017;30(13): 1632-1636.

8. Pandya PP, Kondylios A, Hilbert L, Snijders RJ, Nicolaides KH. Chromosomal defects and outcome in 1015 fetuses with increased nuchal translucency. Ultrasound Obstet Gynecol. 1995;5(1): 15-19.

9. Kagan KO, Avgidou K, Molina FS, Gajewska K, Nicolaides KH. Relation between increased fetal nuchal translucency thickness and chromosomal defects. Obstet Gynecol. 2006;107(1): 6-10.

10. Shankar RK, Backeljauw PF. Current best practice in the management of Turner syndrome. Therapeutic Advances in Endocrinology and Metabolism, 2018;9(1): 33-40. 